\title{
Estudo taxonômico das ervas-de-passarinho da Região sul do Brasil: I. Loranthaceae e Santalaceae
}

Taxonomic study of mistletoes from South Brazil: I. Loranthaceae and Santalaceae

Greta Aline Dettke ${ }^{1}$ \& Jorge Luiz Waechter ${ }^{2}$

\begin{abstract}
Resumo
Apresenta-se aqui o estudo taxonômico de Loranthaceae e Santalaceae para a Região Sul do Brasil. Para Loranthaceae, quatro gêneros e sete espécies foram identificadas: Ligaria cuneifolia, Psittacanthus dichroos, Struthanthus martianus, S. polyrhizus, S. sessiliflorus, S. uraguensis e Tripodanthus acutifolius. Psittacanthus hatschbachii é proposto como sinônimo de P. dichroos e $S$. polyrhizus var. oblongifolius como sinônimo de $S$. polyrhizus. Para Santalaceae foi confirmada Eubrachion ambiguum. São apresentadas descrições, comentários sobre as espécies, ilustrações ou fotografias, dados sobre a distribuição geográfica e chaves de identificação para as famílias, gêneros e para as espécies de Struthanthus.
\end{abstract}

Palavras-chave: Eubrachion, Ligaria, Psittacanthus, Struthanthus, Tripodanthus.

\begin{abstract}
The taxonomic treatment of Loranthaceae and Santalaceae of southern Brazil is presented. In Loranthaceae, four genera and seven species were identified: Ligaria cuneifolia, Psittacanthus dichroos, Struthanthus martianus, S. polyrhizus, S. sessiliflorus, S. uraguensis and Tripodanthus acutifolius. Psittacanthus hatschbachii is proposed as a synonym of $P$. dichroos and Struthanthus polyrhizus var. oblongifolius are proposed as a synonym of $S$. polyrhizus. In Santalaceae only one genus and species was confirmed: Eubrachion ambiguum. We present identification keys for the families and genera of mistletoes of southern Brazil. We provide morphological descriptions, taxonomic and distribution comments, and illustrations or photographs of plant structures.
\end{abstract}

Key words: Ligaria, Psittacanthus, Struthanthus, Tripodanthus, Eubrachion.

\section{Introdução}

$\mathrm{Na}$ classificação atual das Angiospermas (APGIII 2009) as plantas parasitas estão distribuídas em 12 ordens, totalizando aproximadamente 4.350 espécies no Reino Vegetal. Dentre estas ordens, Santalales destaca-se por possuir mais da metade das espécies, distribuídas em 18 famílias e 160 gêneros (Nickrent et al. 2010).

Cinco famílias de Santalales são compostas parcial ou totalmente por ervas holo ou hemiparasitas sobre ramos de angiospermas ou gimnospermas, denominadas popularmente de ervas-de-passarinho: Amphorogynaceae, Loranthaceae, Misodendraceae, Santalaceae e
Viscaceae (Nickrent et al. 2010). Destas, somente Loranthaceae, Santalaceae e Viscaceae ocorrem no Brasil (Arruda et al. 2012).

Loranthaceae é a maior família de Santalales, formada por 75 gêneros e ca. 990 espécies (Nickrent 2013). Poucas espécies ocorrem em áreas temperadas da América do Sul, Ásia, Austrália, Europa e Nova Zelândia, sendo a maior diversidade encontrada nas áreas tropicais, especialmente em ambientes secos sazonais da África e Austrália (Vidal-Russell \& Nickrent 2008). Com exceção de três gêneros monotípicos arbustivos ou arbóreos hemiparasitas de raízes, Loranthaceae é composta predominantemente por ervas-de-passarinho, que

Este artigo possui material adicional em sua versão eletrônica.

${ }^{1}$ Universidade Federal do Rio Grande do Sul, Av. Bento Gonçalves, 9500, 91501-970, Porto Alegre, RS, Brasil. gretadet@yahoo.com.br

${ }^{2}$ Universidade Federal do Rio Grande do Sul, Depto. Botânica, Av. Bento Gonçalves, 9500, 91501-970, Porto Alegre, RS, Brasil. jorgew.bio@gmail.com 
recebem este nome popular, pois têm as aves como principais agentes dispersores de suas sementes (Kuijt 1969).

No Brasil, estão presentes 12 gêneros e ca. 120 espécies de Loranthaceae. A maior diversidade está no Cerrado e na Amazônia, porém são importantes componentes em diversos tipos de ambientes e nas demais regiões fisiográficas do país (Arruda et al. 2012).

Santalaceae é composta por 11 gêneros e cerca de 70 espécies. A família ocorre em todas as regiões tropicais do mundo e apenas no hemisfério Sul se estende até as regiões subtropicais (Nickrent 2013). É composta predominantemente por espécies herbáceas hemiparasitas de raízes, com poucos gêneros hemiparasitas de ramos, dos quais somente Antidaphne e Eubrachion ocorrem no Brasil, somando cinco espécies (Arruda et al. 2012).

Apesar de vários tratamentos abordarem Santalaceae em sentido amplo (ex. APG III 2009, Caires \& Dettke 2010), no qual Viscaceae está incluída, optamos pela circunscrição de famílias proposta por Nickrent et al. (2010), no qual os oito clados reconhecidos por Der \& Nickrent (2008) são aceitos como famílias distintas, baseados na monofilia e na concisão de características morfológicas. Embora Santalaceae sensu APG III (2009) seja monofilética, conforme indicam estudos de filogenia molecular (Der \& Nickrent 2008), o grupo é morfologicamente muito diverso e não possui sinapomorfias morfológicas claras, o que dificulta o seu reconhecimento como família e sua separação de famílias próximas, como Opiliaceae (Nickrent et al. 2010).

A literatura sobre Loranthaceae e Santalaceae no Sul do Brasil é escassa. Somente o trabalho de Rizzini (1968) apresenta o tratamento taxonômico das espécies ocorrentes em Santa Catarina, o qual registra quatro táxons para Loranthaceae e um para Santalaceae. A listagem mais recente (Caires \& Dettke 2010) compila a ocorrência de 14 táxons dessas famílias para a Região Sul. Assim sendo, este trabalho tem por objetivo o estudo taxonômico das espécies pertencentes às famílias Loranthaceae e Santalaceae no Sul do Brasil, visando contribuir para a delimitação e reconhecimento das espécies confirmadas e para o estudo da biodiversidade de importantes domínios fitogeográficos como a Floresta Atlântica e o Pampa. O presente trabalho fornece chaves para identificação dos gêneros e espécies, ilustrações e fotografias, dados ecológicos e de distribuição geográfica, além de comentários taxonômicos e nomenclaturais.

\section{Material e Métodos}

Foram analisadas aproximadamente 1.270 exsicatas de Loranthaceae e Santalaceae do Sul do Brasil, depositadas em herbários brasileiros e internacionais, e provenientes de expedições de coletas na região realizadas entre os anos de 2009 e 2011. Os acrônimos dos herbários consultados são mencionados de acordo com Thiers (continously updated): $\mathrm{BA}^{*}, \mathrm{BAA}^{*}, \mathrm{BAB}^{*}, \mathrm{BAF}^{*}, \mathrm{BR}, \mathrm{C}$, CGMS, CORD*, CRI, CTES*, ESA, F, FCO, FCQ, FLOR*, FURB, HAL, HAS*, HBR, HCF* , HDCF, HFC, HRB, HUCS, HUEM*, HURG, ICN*, JOI*, K, LEB, M, MBM*, MO, NY, P, PACA*, PEL, R*, RB*, S, SCP, SI*, SMDB, UPCB*. Aqueles seguidos de asterisco foram revisados pessoalmente. O material coletado foi herborizado e incorporado à coleção do Herbário ICN (Instituto de Biociências, Universidade Federal do Rio Grande do Sul).

As espécies são apresentadas em ordem alfabética de família e de gêneros. São apresentados apenas os sinônimos aqui designados ou com material tipo no Sul do Brasil. O material examinado mostra apenas um exemplar por estado e todos os espécimes analisados são listados nos Apêndices I e II. Informações sobre floração, frutificação e hospedeiros foram obtidas das exsicatas e observações em campo. A terminologia utilizada para a descrição foliar segue Ellis et al. (2009).

As coletas foram georreferenciadas por meio das informações constantes nas fichas de catálogo (com atualização em alguns casos) e, quando estas informações foram insuficientes, foram anotadas as coordenadas da sede do município. Os mapas foram elaborados com o software de Sistema de Informação Geográfica ArcGIS 9.3 (ESRI®) e apresentam somente a ocorrência na região de estudo. A terminologia para domínios fitogeográficos e formações vegetais está de acordo com IBGE (2012).

\section{Resultados}

Na Região Sul do Brasil, foi confirmada a ocorrência de sete espécies de Loranthaceae, pertencentes a quatro gêneros: Ligaria, Psittacanthus, Tripodanthus e Struthanthus. Para Santalaceae foi confirmada a presença de apenas uma espécie, pertencente ao gênero Eubrachion. 


\section{Chave de identificação das famílias de ervas-de-passarinho do Sul do Brasil}

1. Catáfilos presentes ao menos na porção proximal dos entrenós laterais. Viscaceae

1'. Catáfilos ausentes.

2. Plantas com folhas escamiformes; flores menores que $2 \mathrm{~mm}$ compr. Santalaceae

2'. Plantas com folhas expandidas; flores maiores que $5 \mathrm{~mm}$ compr. Loranthaceae

Chave de identificação dos gêneros de Loranthaceae e Santalaceae do Sul do Brasil

1. Plantas com folhas escamiformes 5. Eubrachion

1'. Plantas com folhas expandidas.

2. Plantas dioicas (flores estaminadas e pistiladas)

3. Struthanthus

2'. Plantas monoico-monoclinas (flores perfeitas).

3. Corola menor que $2 \mathrm{~cm}$ compr., alva, lenticelas presentes na face abaxial das folhas

..4. Tripodanthus

3'. Corola maior que $3 \mathrm{~cm}$ compr., amarela ou vermelha, lenticelas ausentes na face abaxial das folhas.

4. Folhas alternas com ápice suberificado, inflorescências unifloras

1. Ligaria

4'. Folhas opostas com ápice não suberificado, inflorescências em díades ou tríades

2. Psittacanthus

\section{Tratamento Taxonômico}

1. Ligaria Tiegh., Bull. Soc. bot. France 42: 345. 1895.

Espécie tipo: Ligaria cuneifolia (Ruiz \& Pav.) Tiegh., Bull. Soc. bot. France 42: 347. 1895.

Ligaria compreende apenas duas espécies de distribuição disjunta, L. cuneifolia (Ruiz \& Pav.) Tiegh., com distribuição mais ampla, que se estende desde o Peru até o Uruguai, e L. teretiflora (Rizzini) Kuijt, endêmica da região do Morro do Chapéu, na Bahia (Kuijt 1990).

1.1 Ligaria cuneifolia (Ruiz \& Pav.) Tiegh., Bull. Soc. bot. France 42: 347. 1895. Loranthus cuneifolius Ruiz \& Pav., Fl. Peruv. 3: 46, fig. 276b. 1802. Psittacanthus cuneifolius (Ruiz \& Pav.) G. Don, Gen. Hist. 3: 416. 1834. Phrygilanthus cuneifolius (Ruiz \& Pav.) Eichler in Mart., Fl. Bras. 5(2): 49. 1868. TIPO: PERU: 20.IX.1778, H. Ruiz L. \& J.A. Pavón s.n. (holótipo: MA, Negative Field Mus: 29462!).

Iconografia: Fl. bras. 5(2): fig. 11.

Ervas hemiparasitas sobre ramos de angiospermas e gimnospermas, heliófitas. Raízes epicorticais ausentes, sistema haustorial hipertrofiado, atingindo até $15 \mathrm{~cm}$ diâm. Caules eretos, pendentes após crescimento; ramos jovens e adultos circulares em seção transversal; entrenós 3-6 × 0,7 cm; superfície lisa nos ramos apicais e fissurada, com lenticelas elípticas, nos ramos basais. Folhas coriáceas, alternas, sésseis, obovadas, $1,7-4,5 \times 0,3-1 \mathrm{~cm}$; base aguda, cuneada; ápice obtuso, truncado ou convexo; ápice glandular nas folhas jovens e suberificado em folhas totalmente expandidas; nervação palmada actinódroma basal, 3 nervuras, somente a base da central distinta. Inflorescência lateral uniflora, 1-2 por axila; pedicelo simples, ca. $1 \mathrm{~cm}$ compr.; cúpula floral tridentada, dentes agudos, ápice suberificado. Flores $3-4 \mathrm{~cm}$ compr.; calículo 3-4 mm compr., ápice tubuloso; pétalas 3-4 × $0,1 \mathrm{~cm}$, ápice suberificado, coloração vermelha; lígula ca. $1 \mathrm{~mm}$ compr.; tubo floral formado pela união da base das pétalas, em antese pétalas reflexas até a região mediana da flor; filetes vermelhos, 1,5-2 cm compr.; anteras 5-6 $61-2 \mathrm{~mm}$, as três inferiores apiculadas; estilete 2,8-3,6 cm compr., estigma levemente trilobado, ca. $0,7 \mathrm{~mm}$ diâm. Frutos 7-10 × 4-6 mm, ovoides, maduros de coloração preta, coronado pelo ápice tubuloso do calículo. Semente 5-8 × 3-4 mm.

Material selecionado: RIO GRANDE DO SUL: Caçapava do Sul, Pedra do Segredo, 15.XII.2008, fl., G.A. Dettke 152 (ICN).

Ligaria cuneifolia ocorre desde o Peru até a região central da Argentina, estendendo-se no leste para o Chile e no oeste para o Uruguai e Sul do Brasil (Amico \& Nickrent 2007). No Sul do Brasil, ocorre somente no Rio Grande do Sul em áreas florestais e parques de espinilhos (Vachellia caven (Molina) Seigler \& Ebinger, Fabaceae) do Pampa, abaixo do paralelo $30^{\circ}$, onde forma grandes populações sobre espécies nativas, 

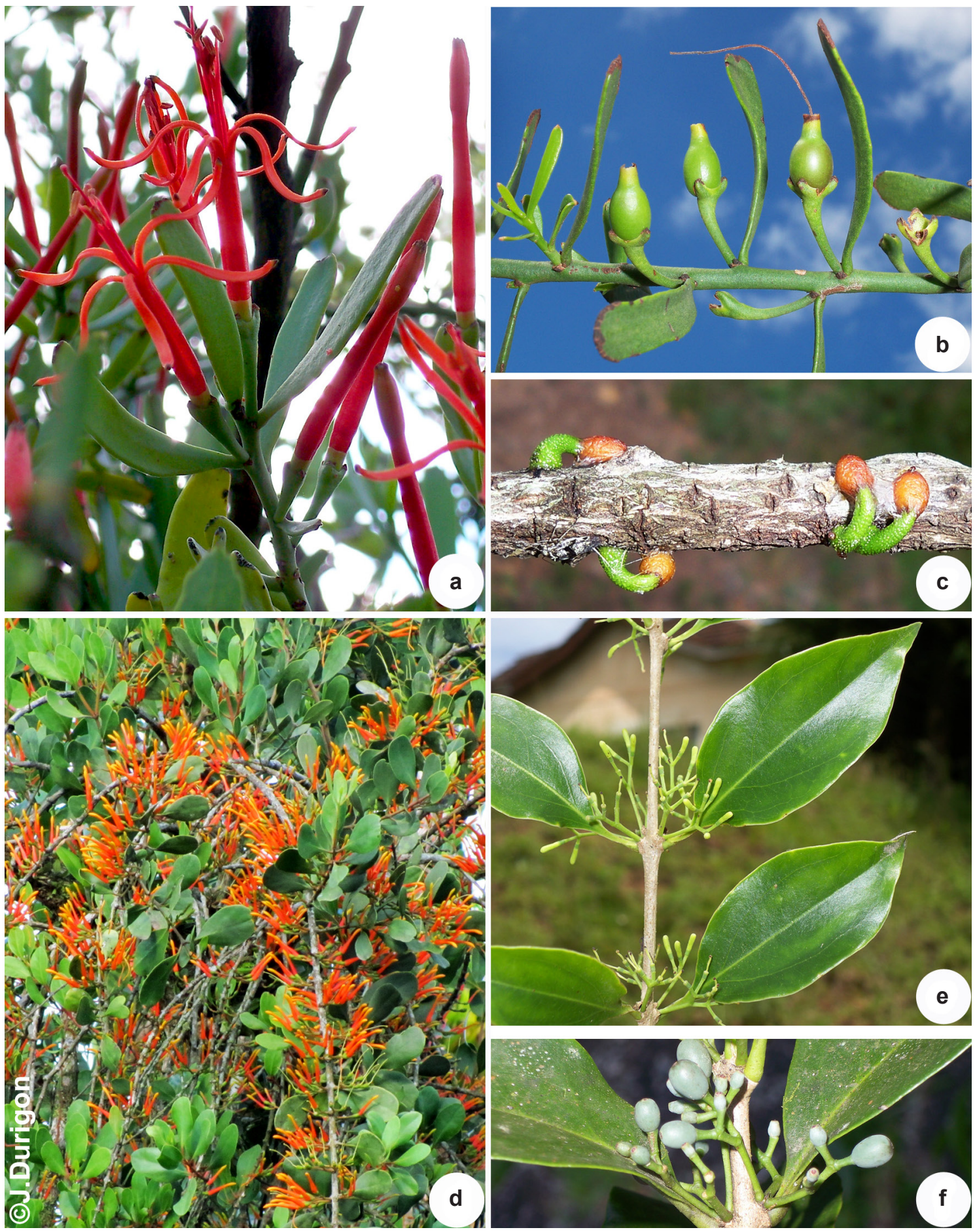

Figura 1 - a-c. Ligaria cuneifolia - a. detalhe de um ramo com flores; b. frutos imaturos; c. sementes germinando sobre um ramo hospedeiro. d. Psittacanthus dichroos - ramos com flores. e-f. Struthanthus martianus - e. ramo com flores de um indivíduo pistilado; f. detalhe dos frutos imaturos.

Figure 1 - a-c. Ligaria cuneifolia - a. detail of a branch with flowers; b. immature fruits; c c. germinating seeds on a branch host. d. Psittacanthus dichroos - branch with flowers. e-f. Struthanthus martianus - e. branch with flowers in a female plant; f. detail of immature fruits. 
preferencialmente em bordas de mata ou árvores isoladas. Apesar de ser encontrada parasitando várias espécies, a associação mais frequente é com espécies de Lithraea Miers e Schinus L. (Anacardiaceae). Neste trabalho, é registrada pela primeira vez sobre outra espécie arbórea hemiparasita de raízes, Jodina rhombifolia (Hook. \& Arn.) Reissek (Cervantesiaceae) e sobre uma gimnosperma, Podocarpus lambertii Klotzsch ex Endl. (Podocarpaceae). Floresce e frutifica entre fevereiro e setembro.

É reconhecida facilmente pelas folhas obovadas com ápice truncado e suberificado, inflorescência composta por uma única flor grande e vermelha. A presença de ápices glandulares e posteriormente a suberificação dos ápices das folhas, da cúpula floral e das flores é bastante interessante do ponto de vista adaptativo e provavelmente está relacionada com a proteção dos meristemas em ambientes com baixa umidade.

2. Psittacanthus Mart., Flora 13: 106. 1830. Espécie tipo: Psittacanthus americanus (L.) Mart., Flora 13: 108. 1830.

Psittacanthus compreende cerca de 120 espécies, sendo o mais rico dentre os gêneros americanos de Loranthaceae, e distribui-se desde o Norte do México ao Sul do Brasil, com maior riqueza no nordeste da América do Sul (Kuijt 2009a). No Brasil, são registradas aproximadamente 42 espécies, com maior riqueza nas regiões de Cerrado e Amazônia (Arruda et al. 2012). No Sul do Brasil, ocorre somente uma espécie deste gênero, Psittacanthus dichroos (Mart.) Mart., que representa o limite austral do gênero na América do Sul.

2.1 Psittacanthus dichroos (Mart.) Mart., Flora 13: 108. 1830. Loranthus dichroos Mart. in Schultes \& Schultes f., Syst. veg. 7: 122. 1829. TIPO: BRASIL. RIO DE JANEIRO: [Provinc. Sebastianopolitana], s.d., Mart. s.n. (holótipo: M[imagem!]). Fig. 1d; 4.

Psittacanthus hatschbachii Kuijt, Syst. Bot. Monogr. 86: 180. 2009. TIPO: BRASIL. PARANÁ: Antonina, $25^{\circ} 28^{\prime} \mathrm{S}, 48^{\circ} 45^{\prime} \mathrm{W}$, sea level, mangrove, on Avicennia schaueriana Stapf \& Leechm. ex Moldenke (Acanthaceae), 29.I.1985, fl., fr.im., G.P. Lewis et al. 1405 (holótipo: K[imagem!]; isótipo: UC (ex-LEA)), syn. nov.

Iconografia: Fl. bras. 5(2): fig. 5.

Ervas hemiparasitas sobre ramos de angiospermas, heliófitas. Raízes epicorticais ausentes, sistema haustorial hipertrofiado, atingindo até $5 \mathrm{~cm}$ diâm. Caules jovens eretos, os mais longos pendentes; elipsoidais a circulares em seção transversal, ramos adultos circulares, atingindo até $2,5 \mathrm{~cm}$ diâm.; entrenós 2-8 × 0,5-1 cm; nós engrossados; superfície fissurada, lenticelas visíveis nos ramos basais, elípticas a alongadas. Folhas coriáceas, opostas, elípticas ou obovadas, 4-8 × 1,5-4 cm; base aguda, decurrente; ápice obtuso, convexo ou arredondado, retuso ou emarginado, mucronado; pecíolo 1-1,5 cm compr.; nervação pinada, a nervura principal conspícua na base. Inflorescências laterais, racemos; brácteas persistentes (fusionadas); flores da tríade pedunculadas, pedúnculo principal e secundários da inflorescência 5-8 $\mathrm{mm}$ compr.; botões florais 3,5-4 cm compr., retos ou eventualmente curvados, ápice agudo; calículo 5-6 $\times 3-4 \mathrm{~mm}$, margem superior irregular; pétalas 3,5-4 $\times 0,2 \mathrm{~cm}$, coloração vermelha na base e amarela no ápice, lígula 1-1,3 mm compr.; estames heterodínamos, anteras 2,9-3,5 mm compr.; estilete ca. $3 \mathrm{~cm}$ compr., torcido na base. Frutos 9-12 × 5-6 mm, elipsoidais, maduros de coloração preta, coronados pelo ápice irregular do calículo. Semente 7-10 × 4-5 mm.

Material selecionado: PARANÁ: Pontal do Sul, 2.I.1967, fl., G. Hatschbach et al. 15607 (MBM, UPCB). SANTA CATARINA: Itapoá, Reserva Volta Velha, margem do Rio Saí-Mirim, 27.XII.1993, fl., R. Negrelle A-984 (UPCB).

Psittacanthus dichroos ocorre com maior frequência nas regiões litorâneas da Floresta Atlântica, desde o Rio Grande do Norte até Santa Catarina, estendendo-se também pelo Cerrado na Bahia (Kuijt 2009a). No Sul do Brasil, ocorre nas áreas costeiras de menor altitude do Paraná e Santa Catarina, para onde é citada pela primeira vez neste trabalho. É encontrada em áreas florestais, restingas e manguezais (até 400 m.s.m.). Parasita espécies arbóreas de Anacardiaceae, Lauraceae, Melastomataceae, Myrtaceae e Vochysiaceae. Floresce e frutifica entre dezembro e abril.

A espécie é reconhecida facilmente pelos ramos pendentes, folhas obovadas com ápice retuso ou emarginado, inflorescências laterais com tríades e flores bicolores. Kuijt (2009a) distinguiu $P$. hatschbachii das demais espécies pela presença de um envoltório suberificado na axila floral, botões florais curvos, pecíolos longos, além da ocorrência da espécie em áreas de mangue, o que segundo o autor é raro no gênero. Estas características são semelhantes às observadas nas populações de $P$. dichroos na região, assim propomos $P$. hatschbachii como sinônimo de $P$. dichroos. No estado do Rio de Janeiro, onde $P$. dichroos é muito frequente, Reif \& Andreata (2011) relataram que a espécie também apresenta grande variação nos ambientes de ocorrência, incluindo áreas de manguezais. 
Chave de identificação para as espécies de Struthanthus no Sul do Brasil

1. Folhas coriáceas; flores da tríade pedunculadas 3.1 Struthanthus martianus

1'. Folhas carnosas; flores da tríade sésseis.

2. Inflorescências sésseis. 3.3 Struthanthus sessiliflorus

2'. Inflorescências pedunculadas.

3. Inflorescências numerosas por axila foliar, racemos..............3.4 Struthanthus uraguensis 3'. Inflorescência única por axila foliar, corimbos 3.2 Struthanthus polyrhizus

3. Struthanthus Mart., Flora 13: 102-103. 1830. Espécie tipo: Struthanthus syringifolius (Mart.) Mart., Flora 13: 105. 1830.

Ervas perenes; dioico-diclinas; hemiparasitas sobre ramos de gimnospermas e angiospermas; heliófitas ou esciófitas. Raízes epicorticais presentes ou não, cilíndricas formando haustórios secundários. Caules eretos, pendentes ou volúveis; ramos jovens com formato quadrangular, circular ou rômbico em seção transversal; ramos adultos circulares; superfície lisa, áspera ou fissurada, lenticelas visíveis ou não. Folhas coriáceas a carnosas; simples; pecioladas, raramente sésseis; opostas ou subopostas; folhas jovens hamatocurvadas ou não; nervação pinada, normalmente somente a nervura primária visível. Inflorescências laterais ou terminais; racemos, espigas, corimbos ou glomérulos; cima como unidade floral básica, uma flor terminal e duas laterais, opostas, formando uma tríade, envoltas ou não por uma cúpula originada pela fusão das brácteas. Botões florais clavados, das flores estaminadas mais largos no ápice que das flores pistiladas. Flores entomófilas; menores que 1,5 cm compr.; sésseis ou pedunculadas; um calículo envolve o ovário; cálice ausente; corola dialipétala, hexâmera, raro pentâmera, pétalas valvares alongadas, reflexas na antese, coloração castanha, alvas, creme a esverdeadas; androceu com 6 estames epipétalos, heterodínamos, sendo 3 deles mais curtos e alternados com os demais, filetes alvos, anteras tetrasporangiadas, dorsifixas, versáteis, com deiscência rimosa, grãos de pólen tricolpados ou tricolporados, exina psilada, imperfurada a punctitegilada, raramente estriadarugulada; nas flores pistiladas, os estaminódios possuem antera atrofiada, basifixa, branca; gineceu com ovário ínfero, tricarpelar, rudimentos seminais ategumentados, com crescimento intrusivo no estilete, disco nectarífero na base do estilete, estilete reto ou torcido, estigma globoso, papilado, trilobado ou não; nas flores estaminadas, disco nectarífero presente e pistilódio presente ou ausente. Frutos pomídeos viscídeos; globosos, elípticos, oblongos, ovados ou obovados; epicarpo coriáceo; frutos maduros de coloração amarela, laranja, vermelha ou preta, por vezes bicolores; viscina envolvendo o pólo radicular. Semente única; ategumentada; endosperma presente e clorofilado; embrião reto; dois cotilédones.

Struthanthus possui entre 60-70 espécies que ocorrem desde o México até a região central da Argentina e Uruguai (Abbiatti 1946; Rizzini 1956). No Brasil, Rizzini $(1950,1956)$ contabilizou aproximadamente 45 espécies, ao passo que a listagem mais recente aponta 57 espécies e seis variedades, sendo mais diverso na Floresta Atlântica, seguido pelo Cerrado e Amazônia e com menor número de espécies na Caatinga e Pampa (Caires \& Dettke 2010; Arruda et al. 2012).

No Sul do Brasil são encontradas quatro espécies, distribuídas em diversos ambientes, sendo mais comuns na Floresta Atlântica.

3.1 Struthanthus martianus Dettke \& Waechter, Phytotaxa 57: 7, fig. 1. 2012. Struthanthus vulgaris Mart. ex Eichler, Fl. Bras.1868: 85. Fig. $27 \&$ 28.VIII), nom. illeg. TIPO: BRASIL. RIO DE JANEIRO: [Sebastianopolitani]: in Guarea trichilioide, September 1833, B. Luschnath s.n. (holótipo BR533439 [imagem!]). Figs. 1e-f; 4. Iconografia: Fl. bras. 5(2): fig. 27 (como Struthanthus vulgaris).

Ervas hemiparasitas sobre ramos de angiospermas, heliófitas. Raízes epicorticais ausentes, sistema haustorial hipertrofiado, atingindo até $5 \mathrm{~cm}$ diâm. Caules eretos, pendentes após crescimento; ramos jovens com formato circular ou elipsoidal em seção transversal, ramos adultos circulares; entrenós $2-8 \times 0,3-$ $0,7 \mathrm{~cm}$; nós engrossados; superfície lisa a estriada, esbranquiçada; lenticelas frequentemente visíveis nos ramos apicais, circulares a elípticas, maiores e alongadas nos ramos basais. Folhas coriáceas, opostas, eventualmente subopostas, elípticas, oblongas ou ovadas, folhas jovens não hamato-curvadas, 4-12 × 1,2-7 cm; base 
aguda ou obtusa, decurrente; ápice agudo, acuminado; superfície adaxial lustrosa; nervação pinada, nervura principal conspícua, nervuras secundárias normalmente visíveis; pecíolo 5-11 $\mathrm{mm}$ compr. Inflorescências laterais, 1-5 por axila, racemos; brácteas decíduas; tríade sem cúpula, flores da tríade pedunculadas; pedúnculo principal da inflorescência de 0,5-1,5 cm compr., pedúnculos secundários de $0,3-1 \mathrm{~cm}$ compr.; flores estaminadas 5-6 mm compr., calículo 0,5-1 mm compr., pétalas 4-5 × 0,7 mm, coloração esverdeada, filete carnoso, anteras ca. $2 \times 1 \mathrm{~mm}$, pistilódio presente; flores pistiladas 5-6 $\mathrm{mm}$ compr., calículo 1-2 mm compr., pétalas 3-5 × $0,5 \mathrm{~mm}$, estilete reto, estigma levemente trilobado. Frutos 5-7 × 4-5 mm, obovados, maduros de coloração preta. Semente ca. $4 \times 3 \mathrm{~mm}$.

Material selecionado: PARANÁ: Campo Largo, Bateias, 1.II.2011, fl., G.A. Dettke 557 (ICN). SANTA CATARINA: Mafra, 4.I.1962, fl., R. Reitz \& R.M. Klein 11517 (HBR, RB).

Struthanthus martianus é endêmica do Brasil, ocorre desde a Bahia até Santa Catarina, em ambientes do Cerrado e Floresta Atlântica (Caires \& Dettke 2010). No Sul do Brasil ocorre frequentemente em áreas litorâneas de mangues e restingas, na Floresta Ombrófila Densa, estendendo-se até a Floresta Ombrófila Mista e áreas relictuais de Cerrado no Paraná. O limite austral de sua distribuição é na região do Vale do Itajaí. A espécie é registrada como parasita de várias espécies arbóreas de Fabaceae, Lauraceae, Myrtaceae, Phyllanthaceae, Rutaceae e Sapindaceae, entre outras, sem aparentemente mostrar uma associação frequente com alguma delas. Floresce e frutifica entre janeiro e setembro.

A espécie é reconhecida pela ausência de raízes epicorticais, ramos eretos, somente pendentes nos ramos de maior comprimento e ramos com superfície esbranquiçada, folhas coriáceas com face adaxial lustrosa e ápice acuminado, inflorescências com flores das tríades pedunculadas. A espécie é frequentemente confundida nos herbários e em campo com Tripodanthus acutifolius, que também é frequente onde ocorre $S$. martianus e difere da espécie aqui tratada por possuir raízes epicorticais, caules verdes ou castanhos, nunca esbranquiçados, folhas com a face abaxial com lenticelas circulares (pontos pretos), inflorescências maiores e mais complexas, laterais e terminais, flores maiores, odoríferas, perfeitas, com pétalas alvas.
3.2 Struthanthus polyrhizus (Mart.) Mart., Flora 13: 105. 1830. Loranthus polyrhizus [polyrrhizos] Mart., in Schultes \& Schultes, Syst. Veg. 7: 139140. 1829. TIPO: BRASIL. BAHIA: Rio das Almas, Mart. s.n. (holótipo: M, Negative Field Mus: 19038!).

Figs. 1a-c; 4.

Struthanthus polyrhizus var. oblongifolius Eichler, in Mart., Fl. Bras. 5(2): 71. 1868. TIPO: BRASIL. SÃO PAULO: Burchell 4090 (lectótipo, designado por Kuijt (1994): BR[imagem!]; isolectótipo: P[imagem!]), syn. nov.

Iconografia: Fl. bras. 5(2): fig. 28I.

Ervas hemiparasitas sobre ramos de angiospermas, heliófitas ou esciófitas. Raízes epicorticais presentes, haustórios secundários se desenvolvendo no contato dos ramos com o hospedeiro. Caules pendentes com ápices volúveis, flageliformes; ramos jovens eretos, rômbicos ou elípticos em seção transversal, ramos adultos circulares; entrenós 2,5-10 × 0,3-0,5 cm; nós achatados; superfície lisa, verde; lenticelas visíveis nos ramos basais, circulares. Folhas carnosas, opostas, frequentemente subopostas, elípticas, oblongas ou obovadas, folhas jovens não hamatocurvadas, 3-7 × 1,5-3 cm; base aguda, decurrente; ápice agudo ou obtuso, convexo ou arredondado, eventualmente retuso ou emarginado, mucronado; nervação pinada, nervura principal conspícua, nervuras secundárias pouco visíveis; pecíolo 3-6 mm compr. Inflorescências laterais, normalmente uma por axila, corimbos; brácteas persistentes; tríade com cúpula, flores da tríade sésseis; pedúnculo principal da inflorescência $1-1,5 \mathrm{~cm}$ compr., pedúnculos secundários $0,4-1 \mathrm{~cm}$ compr.; flores estaminadas 4-5 mm compr., calículo ca. 0,5 mm compr., pétalas 3,5-4,5 × 0,6 mm, coloração esverdeada, filete carnoso, anteras $1,5 \times 0,8 \mathrm{~mm}$, pistilódio ausente; flores pistiladas $3-5 \mathrm{~mm}$ compr., calículo 1-1,5 mm compr., pétalas 2,5-4 × 0,4 mm, estilete reto, estigma levemente trilobado. Frutos 6-8 × 4-5 mm, oblongos, maduros de coloração preta. Semente ca. $5 \times 4 \mathrm{~mm}$.

Material selecionado: PARANÁ: Antonina, estrada para Guaraqueçaba, 15.X.2009, fl., G.A. Dettke 410 (ICN). RIO GRANDE DO SUL: Dom Pedro de Alcântara, Mata do Baptista, 14.IX.2008, fl., G.A. Dettke 414 (ICN). SANTA CATARINA: Rio dos Cedros, 11.XI.2010, fl., G.A. Dettke 463 (ICN).

Struthanthus polyrhizus ocorre desde o Nordeste até o Sul do Brasil, sendo encontrada na Floresta Atlântica e no Cerrado (Caires \& Dettke 2010). Ocorre nos três estados da Região Sul do 
Brasil, em áreas da Floresta Ombrófila Densa e Mista e têm como limite sul de distribuição a região de Osório, no Rio Grande do Sul. Ocorre sobre uma variedade grande de hospedeiros, incluindo espécies exóticas e cultivadas, porém apresenta frequente associação com espécies de Alchornea Sw. e Sebastiania Spreng. (Euphorbiaceae) e Miconia Ruiz \& Pav. (Melastomataceae). Floresce e frutifica ao longo de todo o ano, com fases mais acentuadas entre novembro e junho.

A espécie é reconhecida pelos ramos com ápices volúveis, normalmente achatados ou com formato rômbico, ápice das folhas normalmente retuso ou emarginado e inflorescências do tipo corimbo.

Eichler (1868) descreveu a variedade $S$. polyrhizus var. oblongifolius, cujo espécime apresenta folhas oblongas. Não consideramos esta uma variedade consistente, pois observamos grande variação da forma foliar nas populações encontradas, bem como no material de herbário e, assim, propomos esta variedade como sinônimo. Os materiais apresentados por Rizzini (1968) apresentam muita sobreposição de características e, por vezes, em um mesmo ramo é possível encontrar várias formas do limbo e de ápice foliar. De maneira geral, as características vegetativas auxiliam, porém não determinam a circunscrição de espécies de Struthanthus; as características determinantes e aparentemente mais conservadas são as estruturas florais, em especial a inflorescência (ver comentários adicionais em $S$. uraguensis e $S$. sessiliflorus).

3.3 Struthanthus sessiliflorus Kuijt, Brittonia 61(2): 162, fig. 12. 2009. TIPO: BRASIL, PARANÁ, Mun. Piraquara, Medianeira, O.S. Ribas et al. 5763 (holótipo: UC (ex-LEA); isótipos: MBM!, MO).

Fig. 4.

Iconografia: Brittonia 61(2): fig. 12.

Ervas hemiparasitas sobre ramos de angiospermas, heliófitas. Raízes epicorticais presentes, haustórios secundários se desenvolvendo no contato dos ramos com o hospedeiro. Caules pendentes com ápices volúveis, flageliformes, frequentemente vários ramos enrolados em torno de si; circulares em seção transversal, ramos adultos circulares; entrenós 2-10 × 0,3-0,5 cm; superfície lisa, verde; lenticelas visíveis nos ramos basais, circulares. Folhas carnosas, opostas ou subopostas, elípticas ou obovadas, folhas jovens não hamatocurvadas, 2-5 × 1-2,5 cm; base aguda, decurrente; ápice agudo ou obtuso, convexo ou arredondado, mucronado; nervação pinada, nervura principal conspícua na face abaxial, nervuras secundárias não visíveis; pecíolo 5-6 mm compr. Inflorescências laterais, normalmente uma por axila, corimbos sésseis; brácteas persistentes; tríade com cúpula, flores da tríade sésseis; pedúnculo principal da inflorescência ca. $1 \mathrm{~mm}$ compr., pedúnculos secundários 1-3 mm compr.; flores estaminadas 4-5 mm compr., calículo ca. 0,5 mm compr., pétalas 3,5-4,5 × 0,7 mm, coloração esverdeada ou castanha, filete carnoso, anteras ca. 1,5 ×0,8 mm, pistilódio ausente; flores pistiladas $4-5 \mathrm{~mm}$ compr., calículo 1-2 mm compr., pétalas 3-4 × 0,4 mm, estilete reto, estigma levemente trilobado. Frutos 6-8 × 4-5 mm, oblongos, maduros de coloração preta. Semente ca. $5 \times 4 \mathrm{~mm}$.

Material selecionado: PARANÁ: Guaratuba, Sítio Santa Bárbara, 14.II.2004, f1., O.S. Ribas et al. 5893 (MBM - parátipo). SANTA CATARINA: Garuva, Morro Monte Crista, 8.III.2008, fr., J. Cordeiro \& J.M. Silva 2458 (MBM).

Struthanthus sessiliflorus é endêmica do Brasil e registrada somente no Paraná e Santa Catarina (Kuijt 2009b), ocorrendo em áreas de Floresta Ombrófila Densa e Ombrófila Mista. Há poucos hospedeiros relatados para este táxon, entre eles Laguncularia C.F. Gaertn. (Combretaceae), Symplocos Jacq. (Symplocaceae), Croton L. (Euphorbiaceae) e Tibouchina Aubl. (Melastomataceae). Floresce e frutifica entre outubro e março.

A espécie é reconhecida pelos ramos com ápices volúveis e cilíndricos, folhas geralmente obovadas e inflorescências sésseis do tipo corimbo, congestas nas axilas foliares. Vegetativamente é parecida com S. uraguensis, mas esta possui inflorescências do tipo racemo, com pedúnculo maior que 0,5 cm compr. As inflorescências de $S$. sessiliflorus são do mesmo tipo que $S$. polyrhizus, mas com encurtamento de quase todos os entrenós, tornando-as congestas.

3.4 Struthanthus uraguensis (Hook. \& Arn.) G. Don, Gen. Syst. 3: 410. 1834. Loranthus uraguensis Hook. \& Arn., Bot. Misc. 3: 358. 1833. TIPO: URUGUAI: upon Laurels and Myrtales, Tweedie s.n. (holotype: K[imagem!]). $\quad$ Figs. 2d-e; 4.

Iconografia: Fl. bras. 5(2): fig. 21 (como Struthanthus complexus).

Ervas hemiparasitas sobre ramos de angiospermas, heliófitas. Raízes epicorticais presentes, haustórios secundários se desenvolvendo 
no contato dos ramos com o hospedeiro ou os próprios ramos. Caules pendentes com ápices volúveis, flageliformes, frequentemente vários ramos enrolados em torno de si; circulares ou elípticos em seção transversal, ramos adultos cilíndricos; entrenós 2-7 × 0,2-0,5 cm; superfície lisa, verde; lenticelas visíveis nos ramos basais, circulares ou alongadas. Folhas carnosas, opostas, frequentemente subopostas, elípticas ou obovadas, folhas jovens não hamato-curvadas, $2-4 \times 0,8-1,5$ $\mathrm{cm}$; base aguda, decurrente; ápice agudo ou obtuso, convexo ou arredondado, mucronado; nervação pinada, nervura principal conspícua na face abaxial, nervuras secundárias não visíveis; pecíolo 5-6 $\mathrm{mm}$ compr. Inflorescências laterais, $1-6$ por axila, racemos; brácteas persistentes; tríade com cúpula, flores da tríade sésseis; pedúnculo principal da inflorescência $0,5-2 \mathrm{~cm}$ compr., pedúnculos secundários de 0,5-1 cm compr.; flores estaminadas 4-6 mm compr., calículo ca. 0,5 mm compr., pétalas 3,5-5,5 × 0,8 mm, coloração esverdeada ou castanha, filete carnoso, anteras ca. 1,5 $\times 0,8 \mathrm{~mm}$, pistilódio ausente; flores pistiladas $4-5 \mathrm{~mm}$ compr., calículo 1-2 mm compr., pétalas 3-4 × 0,4 $\mathrm{mm}$, estilete reto, estigma levemente trilobado. Frutos 7-10 × 5-6 mm, oblongos, maduros de coloração preta ou bicolores, vermelhos na base e ápice. Semente ca. $6 \times 4 \mathrm{~cm}$.

Material selecionado: PARANÁ: Cerro Azul, 17.X.2009, fl., G.A. Dettke 335 (ICN). RIO GRANDE DO SUL: Barra do Quaraí, Parque Estadual do Espinilho, 2.XII.2010, fl., fr., G.A. Dettke 490 (ICN). SANTA CATARINA: Campo Belo do Sul, Rodovia SC-458, 4.III.2010, fl., G.A. Dettke 329 (ICN).

Struthanthus uraguensis ocorre na Argentina, Brasil e Uruguai; no Brasil ocorre em ambientes da Floresta Atlântica, Cerrado, Amazônia e Pampa (Caires \& Dettke 2010). No Sul do Brasil, é encontrada nos três estados, preferencialmente em regiões de maior altitude (acima dos 600 m.s.m.) na Floresta Ombrófila Mista e em florestas ribeirinhas do Pampa, por onde se estende até o Uruguai e a Argentina; poucas populações são encontradas na Floresta Estacional do oeste do Rio Grande do Sul. Parasita vários táxons de angiospermas, mas frequentemente é encontrada sobre espécies de Schinus L. (Anacardiaceae), Baccharis L. e Eupatorium L. (Asteraceae) e, mais no extremo sul, sobre Vachellia Wight \& Arn. (Fabaceae). Floresce e frutifica entre novembro e julho.

A espécie é reconhecida pelos ramos cilíndricos, que formam grandes emaranhados sobre os próprios ramos e os do hospedeiro, formando haustórios nos contatos entre eles; as folhas geralmente são elípticas e as inflorescências são do tipo racemo. A espécie é confundida com muita frequência com $S$. polyrhizus, que possui distribuição maior na Floresta Ombrófila Densa, ramos jovens achatados ou rômbicos, folhas normalmente mais largas e com o ápice retuso e inflorescência do tipo corimbo (ver comentários adicionais em $S$. sessiliflorus).

A espécie é a única da região a apresentar frutos bicolores (Fig. 3e), com base preta e região mediana e apical vermelha. Esta característica foi observada na maioria das populações da região, porém em alguns casos no mesmo ramo é possível encontrar frutos maduros bicolores e frutos inteiramente pretos.

4. Tripodanthus (Eichler) Tiegh., Bull. Soc. bot. France 42: 178. 1895. Phrygilanthus subgen. Tripodanthus Eichler, in Mart. Fl. Bras. 5(2): 48. 1868.

Espécie tipo: Tripodanthus acutifolius (Ruiz \& Pav.) Tiegh., designado por Kuijt, Fl. Ecuador 24: 142.1986.

Tripodanthus é composto por apenas três espécies que ocorrem na América do Sul. Tripodanthus belmirensis Roldan \& Kuijt é endêmica da Colômbia; Tripodanthus flagellaris (Cham. \& Schltdl.) Tiegh. ocorre no Uruguai e Argentina e Tripodanthus acutifolius (Ruiz \& Pav.) Tiegh. é a espécie com distribuição mais ampla, ocorrendo desde a Venezuela até a região central da Argentina, de onde se estende para o Uruguai, Sul do Brasil e para o norte até a Bahia (Roldán \& Kuijt 2005; Amico et al. 2012).

4.1 Tripodanthus acutifolius (Ruiz \& Pav.) Tiegh., Bull. Soc. bot. France 42: 179. 1895. Loranthus acutifolius Ruiz \& Pav., Fl. Peruv. 3: 48. Fig. 274b. 1802. Psittacanthus acutifolius (Ruiz \& Pav.) G. Don, Gen. Syst. 3: 417. 1834. Phrygilanthus acutifolius (Ruiz \& Pav.) Eichler, in Mart., Fl. Bras. 5(2): 49. 1868. TIPO: PERU. HUANUCO: 26.IX.1778, H. Ruíz L. \& J.A. Pavón s.n. (holótipo: MA, Negative Field Mus: 29457!). Figs. 2f-g; 4.

Iconografia: Fl. bras. 5(2): fig. 12 (como Phrygilanthus eugenoides).

Ervas, eventualmente arbustos ou árvores, hemiparasitas sobre ramos e raízes de angiospermas, heliófitas. Raízes epicorticais presentes, formando haustórios secundários no contato com o hospedeiro. Caules pendentes; 

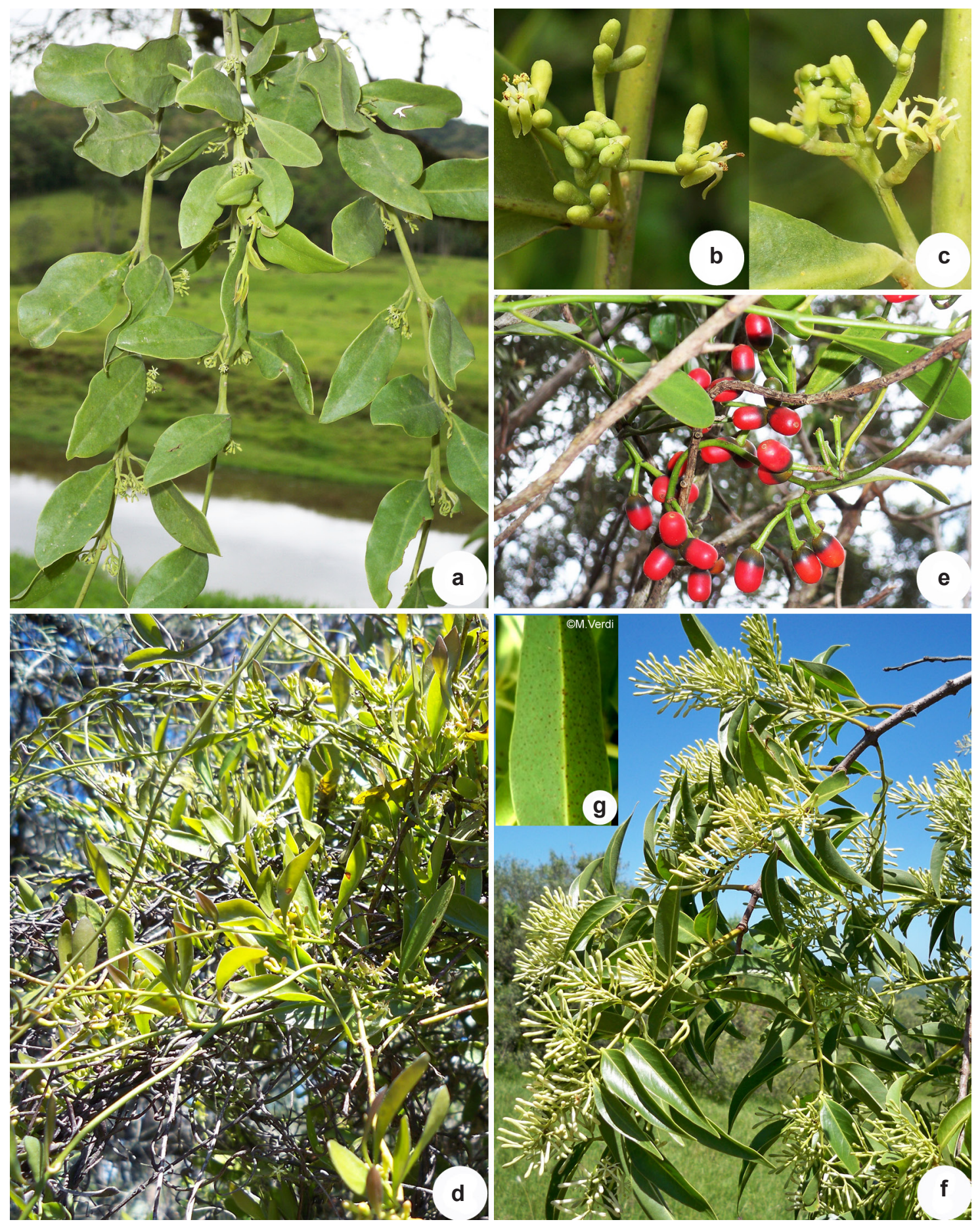

Figura 2 - a-c. Struthanthus polyrhizus - a. ramo com flores de um indivíduo pistilado; b. inflorescência estaminada; c. inflorescência pistilada. d-e. Struthanthus uraguensis - d. ramos com flores de um indivíduo estaminado; e. frutos maduros. f-g. Tripodanthus acutifolius - f. ramo com flores; g. detalhe da face abaxial, onde são visíveis as lenticelas. Figura 2 - a-c. Struthanthus polyrhizus - a. branch with flowers in a female plant; b. male inflorescence; c. female inflorescence. d-e. Struthanthus uraguensis - d. branch with flowers in a male plant; e. mature fruits. f-g. Tripodanthus acutifolius - f. branch with flowers; g. Detail of abaxial surface of the leaves, where they lenticels are visible. 
ramos jovens elipsoidais a circulares em seção transversal, ramos adultos circulares, até $6 \mathrm{~cm}$ diâm.; entrenós $15 \times 0,5-1 \mathrm{~cm}$; superfície fissurada, lenticelas circulares ou elípticas. Folhas coriáceas, opostas, elípticas, oblongas ou ovadas, 4-15 × 2-6 cm, presença de lenticelas na face abaxial, circulares; base aguda ou obtusa, decurrente; ápice agudo, convexo ou acuminado, mucronado; nervação pinada, a nervura principal conspícua, as secundárias inconspícuas; pecíolo 1-1,5 cm compr. Inflorescências laterais e terminais, racemos, geralmente duas ou mais por axila; brácteas caducas; flores da tríade pedunculadas; pedúnculo principal 2-3 cm compr., os secundários $0,8-1,2$ cm compr.; botões florais $1-1,5 \mathrm{~cm}$ compr., retos, ápice agudo; calículo ca. $3 \mathrm{~mm}$ compr.; pétalas de coloração amarela ou branca, 0,8-1,3 × 0,15 mm, lígula ausente; estilete ca. 1,2 cm compr.; estames heterodínamos, anteras ca. 2 x $1 \mathrm{~mm}$. Frutos 9-12 $\times$ 5-6 mm, oblongos, maduros de coloração preta. Semente $8-10 \times 4-5 \mathrm{~mm}$.

Material selecionado: PARANÁ: Guarapuava, 25 km N de Guarapuava para Pitanga, 7.V.1967, fr., J.C. Lindeman \& J.H. Haas 5263 (MBM). RIO GRANDE DO SUL: Lavras do Sul, Rincão do Inferno, 14.I.2010, fl., G.A. Dettke 303 (ICN). SANTA CATARINA: Campo Belo do Sul, rodovia SC-458, 4.III.2010, fl., G.A. Dettke 322 (ICN).

Tripodanthus acutifolius é a única espécie do gênero que ocorre no Brasil; distribui-se pelo Cerrado, Floresta Atlântica e Pampa. Ocorre nos três estados do Sul do Brasil, sendo uma espécie muito comum em áreas de Floresta Ombrófila Mista e áreas florestais e ribeirinhas do Pampa; é pouco frequente na Floresta Ombrófila Densa e Floresta Estacional. No Pampa foram observados os maiores indivíduos da espécie, que se destaca muito na vegetação durante a época de floração. Embora germine exclusivamente sobre os ramos dos hospedeiros, após o estabelecimento são produzidas raízes epicorticais que podem parasitar outros ramos ou crescerem até o solo e estabelecer novas conexões com as raízes do hospedeiro ou de outras espécies das proximidades. Eventualmente, a conexão primária é perdida e a espécie assume aspecto arbustivo ou arbóreo, cujo crescimento em espessura dos caules permite a autossustentação, porém sem perder as conexões haustoriais, de modo que a espécie permanece hemiparasita. Foi observada sobre uma variedade muito grande de hospedeiros nativos e exóticos, não sendo observada associação frequente sobre alguma delas; muitas vezes um indivíduo estabelecido sobre um hospedeiro é capaz de formar novos haustórios sobre outros indivíduos próximos. Floresce e frutifica entre novembro e julho.

A espécie é reconhecida facilmente pelos ramos pendentes, folhas coriáceas com ápice agudo, face adaxial da folha com lenticelas (Fig. $3 \mathrm{~g}$ ), longas inflorescências laterais e terminais, flores perfeitas, com pétalas alvas e bastante perfumadas (odor doce) (ver comentários adicionais em Struthanthus martianus).

5. Eubrachion Hook. f., Flora Antarct. 2: 291. 1846.

Espécie tipo: Eubrachion arnottii Hook. f., Flora Antarctica 2: 291. 1846. nom. illeg. superfl. [=Eubrachion ambiguum (Hook. \& Arn.) Engl.].

Eubrachion possui somente duas espécies E. ambiguum (Hook. \& Arn.) Engl. e E. gracile Kuijt (Kuijt 1988). O gênero apresenta um padrão anfitropical de distribuição, a área sul abrange as regiões Sudeste e Sul do Brasil, Uruguai e Argentina e a área norte compreende a Colômbia, Venezuela e Caribe (Kuijt 1988). No Brasil ocorre somente Eubrachion ambiguum.

5.1 Eubrachion ambiguum (Hook. \& Arn.) Engl., Nat. Pflanzenfam. 3: 192. 1889. Misc. 3: 356. 1833. TIPO: ARGENTINA. "Upon Myrtles by the River Uruguay," Tweedie s.n. (holotype: K[imagem!]).

Figs. 3a-g; 4.

Eubrachion brasiliense Eichler, in Mart., Fl. Bras. 5(2): 133, Fig. 44. 1868. TIPO: BRASIL. RIO GRANDE DO SUL: "In Brasilia austro-orientali", Sellow s.n. (lectótipo, primeiro passo do lectótipo designado por Kuijt (1988), segundo passo aqui designado: R 56498!).

Ervas hemiparasitas sobre ramos de angiospermas, heliófitas. Raízes epicorticais ausentes, sistema haustorial hipertrofiado, atingindo até $5 \mathrm{~cm}$ diâm. Caules eretos, de coloração verde ou amarelada, até $50 \mathrm{~cm}$ compr.; caule primário 2-10 mm diâm., ramos laterais 1-3 mm diâm. Escamas caducas, peltadas, raramente basifixas na base dos ramos, borda translúcida, levemente ciliada, $1-2 \times 0,7-1,5 \mathrm{~mm}$; escamas jovens das plântulas estreitamente lanceoladas, ca. $3 \times 0,5$ $\mathrm{mm}$. Inflorescências simples, laterais, 10-50 dispostas na porção mediano-superior dos ramos, 7-10 mm compr. na floração e até $12 \mathrm{~mm}$ compr. na frutificação; base da inflorescência com 8-12 brácteas não férteis, persistentes. Flores achatadas, ca. $1 \mathrm{~mm}$ compr., perianto trímero, pétalas laterais 


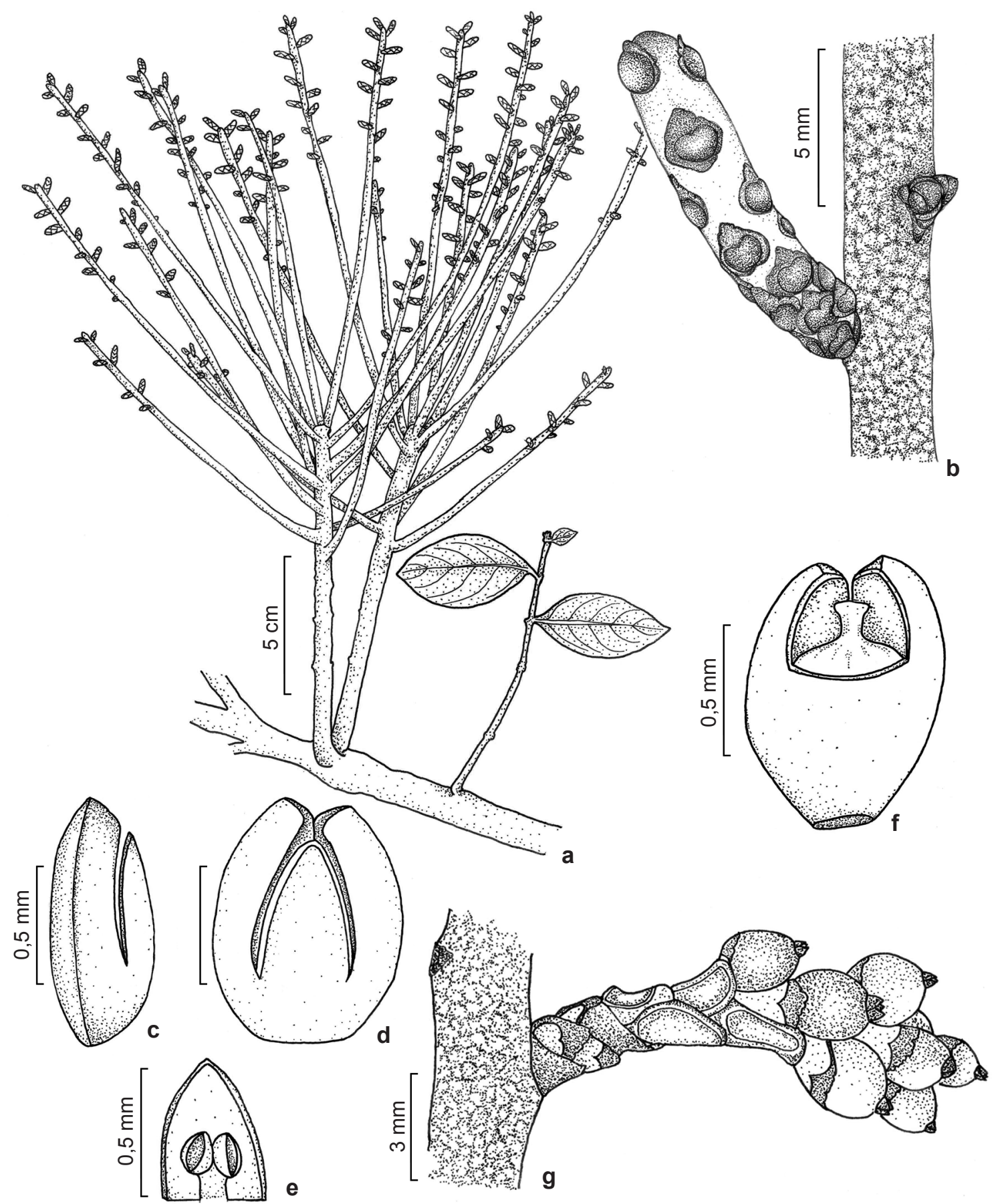

Figura 3 - Eubrachion ambiguum - a. hábito; b. detalhe de um ramo jovem; c. flor estaminada em vista lateral; d. flor estaminada em vista frontal; e. estame; f. flor pistilada em vista frontal, uma pétala removida; g. frutos maduros. (a - Steffen s.n. (PACA 97160); b-e - Dettke \& Lima 166 (ICN); g-Dettke et al. 499 (ICN)).

Figura 3 - Eubrachion ambiguum - a. habit; b. detail of a juvenile branch; c. male flower in a lateral view; d. male flower in a frontal view; e. stamen; f. female flower in a frontal view, one petal removed; g. mature fruit. (a - Steffen s.n. (PACA 97160); b-e - Dettke \& Lima 166 (ICN); g-Dettke et al. 499 (ICN)). 

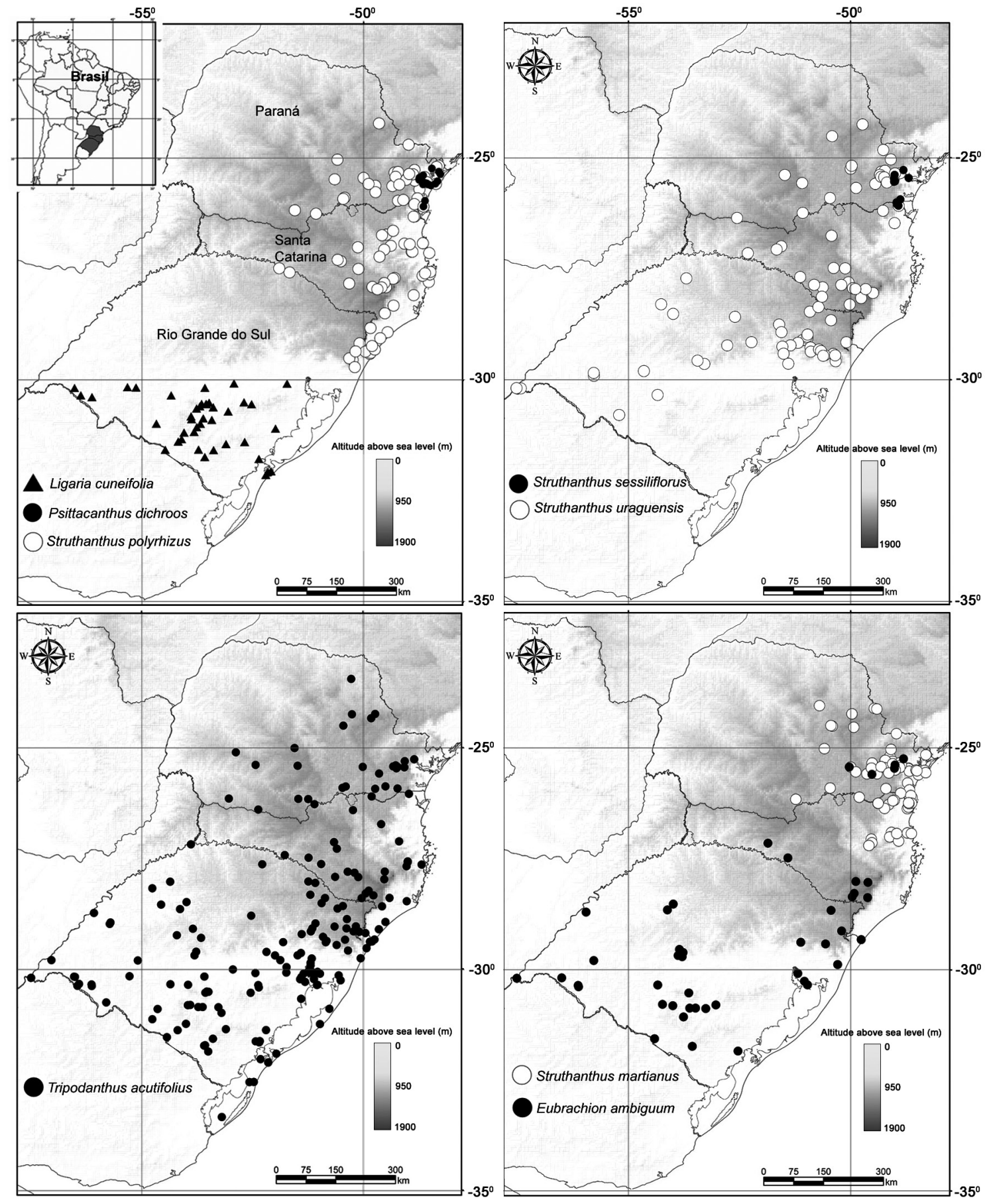

Figura 4 - Coletas de espécies de Loranthaceae e Santalaceae na Região Sul do Brasil. Figure 4 - Collections of Loranthaceae and Santalaceae species from Southern Brazil.

carenadas e dorsal plana e triangular, coloração amarela; flores estaminadas 4-7 basais, subtendidas por bráctea caduca, androceu com 3 estames, filete ca. $0,2 \mathrm{~mm}$ compr., anteras elipsoidais, ca. $0,15 \mathrm{~mm}$ compr.; flores pistiladas subtendidas por brácteas persistentes, estilete ca. 0,1 mm compr. Frutos 2-2,5 $\times 2 \mathrm{~mm}$, epicarpo coriáceo de coloração amarela ou castanha, perianto persistente, viscina 
de coloração translúcida. Semente ca. 0,9 mm diâm.; castanha.

Material selecionado: PARANÁ: Quatro Barras, Rio Taquari, 8.X.1968, fr., G. Hatschbach 19946 (MBM). RIO GRANDE DO SUL: São Martinho da Serra, 12.X.2011, fr., G.A. Dettke \& J. Durigon 988 (ICN). SANTA CATARINA: Concórdia, Planalto, 25.X.1964, fr., L.B. Smith \& R. Reitz 12954 (HBR, R).

Eubrachion ambiguum apresenta, assim como o gênero, uma distribuição disjunta anfitropical, ocorrendo nas regiões Sul e Sudeste do Brasil, Uruguai e Argentina, reaparecendo em várias ilhas do Caribe, como a Jamaica, Haiti, República Dominicana e Porto Rico (Kuijt 1988). Fernández-Alonso et al. (2001) documentaram equivocadamente esta espécie para a Colômbia, a qual se trata de E. gracile, que também ocorre no país vizinho (Venezuela). A espécie apresenta inflorescências terminais compostas, ao contrário de E. ambiguum, que apresenta somente inflorescências laterais simples. No Brasil, E. ambiguum ocorre nas regiões Sudeste e Sul (Caires \& Dettke 2010). Na Região Sul, ocorre nas matas do Pampa, onde forma grandes populações, e mais raramente na Floresta Ombrófila Mista e Ombrófila Densa. Floresce de maio a setembro e frutifica de julho a fevereiro.

Kuijt (1988) salientou a grande afinidade de parasitismo de E. ambiguum com espécies de Myrtaceae. No Sul do Brasil esta associação também pode ser vista com frequência, especialmente com Eugenia uniflora L. Nos campos de altitude do Rio Grande do Sul e Santa Catarina, Acca sellowiana (O. Berg) Burret (Myrtaceae) também é um hospedeiro frequente. Em algumas áreas da Serra do Sudeste do Rio Grande do Sul, foram observadas grandes populações de E. ambiguum sobre Myrsine coriacea (Sw.) R. Br. e M. lorentziana (Mez) Arechav. (Myrsinaceae) (Dettke 288, $289-$ ICN), mesmo com a presença de Myrtaceae (não parasitadas) nas imediações. Para o extremo oeste do Rio Grande do Sul, há também registros de $E$. ambiguum sobre Aspidosperma quebracho-blanco Schltdl. (Apocynaceae), uma árvore típica dos parques de inhanduvás (J.N.C. Marchiori s.n. HDCF 602).

\section{Nomes citados para a Região Sul do Brasil e excluídos neste tratamento}

Phrygilanthus eugenioides (Kunth)

Eichler (Eichler 1868): sinônimo heterotípico de Tripodanthus acutifolius (Ruiz \& Pav.) Tiegh.

Struthanthus andrastylus Eichler (Caires \& Dettke 2010): identificação errônea, material correspondente a Struthanthus polyrhizus (Mart). Mart. Struthanthus flexicaulis Mart. (Caires \& Dettke 2010): identificação errônea, material correspondente a Struthanthus uraguensis (Hook \& Arn.) G. Don.

Struthanthus staphylinus Mart. (Rambo 1951; Caires \& Dettke 2010): identificação errônea, material correspondente a Struthanthus polyrhizus (Mart). Mart.

Tripodanthus flagellaris (Cham. \& Schltdl.) Tiegh. (Eichler 1868; Caires \& Dettke 2010): O holótipo desta espécie apresenta como informação de coleta "Brasilia meridionalis" - Sellow s.n. (HAL 98468), embora a coleta tenha sido atribuída até o momento para o território brasileiro, acreditase que tenha sido coletada no Uruguai, onde Sellow fez parte de sua expedição (Marchiori \& Durlo 1998) e onde a espécie é encontrada em ambientes próximos do Rio Uruguai, entre a divisa do Uruguai e Argentina. Mesmo após vários esforços para coleta na região próxima ao Rio Uruguai em território brasileiro, nenhum indivíduo foi localizado e sua ocorrência é considerada duvidosa para o Brasil.

\section{Agradecimentos}

Os autores agradecem aos curadores dos herbários consultados e ao $\mathrm{CNPq}$, o suporte financeiro (Projeto Universal/Processo 471695/2010-6), à Jaqueline Durigon e Marcio Verdi, a permissão de uso de suas fotografias. Esta é a publicação 11 da série técnica do Grupo de Estudos de Plantas Parasitas-CNPq-Brasil.

\section{Referências}

Abbiatti, D. 1946. Las Lorantáceas argentinas. Revista del Museo de La Plata, Botánica 28: 1-110.

Amico, G.C. \& Nickrent, D.L. 2007. Phylogeography of the argentine mistletoe, Ligaria cuneifolia (Loranthaceae). Darwiniana 45: 63-64.

Amico, G.C.; Vidal-Russel, R.; Garcia, M.A. \& Nickrent, D.L. 2012. Evolutionary history of the South American Mistletoe Tripodanthus (Loranthaceae) Using Nuclear and Plastid Markers. Systematic Botany 37: 218-225.

APG III. 2009. An update of the Angiosperm Phylogeny Group classification for the orders and families of flowering plants: APG III. Botanical Journal of the Linnean Society 161: 105-121.

Arruda, R.; Fadini, R.F.; Carvalho, L.N.; Del-Claro, K.; Mourão, F.A.; Jacobi, C.M., Teodoro, G.S.; van den Berg, E.; Caires, C.S. \& Dettke, G.A. 2012. Ecology of neotropical mistletoes: an important canopy- 
dwelling component of Brazilian ecosystems. Acta Botanica Brasilica 26: 264-274.

Caires, C.S. \& Dettke, G.A. 2010. Loranthaceae, Pp. 1172-1177. In: Forzza, R.C.; Leitman, P.M.; Costa, A.; Carvalho Jr., A.A.; Peixoto, A.L.; Walter, B.M.T.; Bicudo, C.; Zappi, D.; Costa, D.P.; Lleras, E.; Martinelli, G.; Lima, H.C.; Prado, J.; Stehmann, J.R.; Baumgratz, J.F.A.; Pirani, J.R.; Sylvestre, L.S.; Mamede, L.C.; Bastos, M.N.C.; Morim, M.P.; Barbosa, M.R.; Menezes, M.; Hopkins, M.; Secco, R.; Cavalcanti, T. \& Souza, V.C. (orgs.). Catálogo de plantas e fungos do Brasil, vol. 2. Rio de Janeiro, Instituto de Pesquisas Jardim Botânico do Rio de Janeiro.

Der, J.P. \& Nickrent, D.L. 2008. A molecular phylogeny of Santalaceae (Santalales). Systematic Botany 33: 107-116.

Eichler, A.W. 1868. Loranthaceae. In: Martius, C.F.P.V. Flora brasiliensis 5: 1-136, t.1-44.

Ellis, B.; Daly, D.C.; Hickey, L.J.; Johnson, K.R.; Mitchell, J.D.; Wilf, P. \& Wing, S.L. 2009. Manual of leaf architecture. Cornell University Press, New York. 190p.

Fernández-Alonso, J.L.; Schmidt, M.H. \& Roldán, F.J. 2001. El genero Eubrachion Hook. f. (Eremolepidaceae) en Colombia. Revista de la Academia Colombiana de Ciencias Exactas, Físicas y Naturales 25: 21-26

IBGE. 2012. Manual técnico da vegetação brasileira. $2^{\mathrm{a}}$ ed. Manuais Técnicos em Geociências, Rio de Janeiro. 275p.

Kuijt, J. 1969. The biology of parasitic flowering plants. University of California Press, Berkeley. 246p.

Kuijt, J. 1988. Monograph of Eremolepidaceae. Systematic Botany Monographs 18: 1-60.

Kuijt, J. 1990. A second species of Ligaria (Loranthaceae). Brittonia 42: 66-69.

Kuijt, J. 1994. Typification of the names of new world mistletoe taxa (Loranthaceae and Viscaceae) described by Martius and Eichler. Taxon 43: 187-199.

Kuijt, J. 2009a. Miscellaneous mistletoe notes, 48-60: Descriptions of twelve new species of Loranthaceae and Viscaceae. Brittonia 61: 144-162.
Kuijt, J. 2009b. Monograph of Psittacanthus (Loranthaceae). Systematic Botany Monographs 86: 1-361.

Marchiori, J.N.C \& Durlo, M.A. 1998. Friederich Sellow e sua contribuição para as ciências naturais. Ciência \& Ambiente 16: 29-50.

Nickrent, D.L. 2013. The parasitic plant connection. Parasitic Plant Genera and Species, tabela atualizada em 6/III/2012. Disponível em <http:// www.parasiticplants.siu.edu/ParPlantNumbers. pdf $>$. Acesso em 10 setembro 2013.

Nickrent, D.L.; Malécot, V.; Vidal-Russell, R. \& Der, J.P. 2010. A revised classification of Santalales. Taxon 59: 538-558.

Rambo, B. 1951. A imigração da selva higrófila no Rio Grande do Sul. Anais Botânicos do Herbário "Barbosa Rodrigues" 3: 55-91.

Reif, C. \& Andreata, R.H.P. 2011. Contribuição à taxonomia de Loranthaceae no estado do Rio de Janeiro, Brasil. Pesquisas, Botânica 62: 71-115.

Rizzini, C.T. 1950. Struthanti Brasiliae eiusque vicinorum. Revista Brasileira de Biologia 10: 393-408.

Rizzini, C.T. 1956. Pars specialis prodromi monographiae Loranthacearum Brasiliae terrarumque finitimarum. Rodriguésia 30-31: 87-234.

Rizzini, C.T. 1968. Lorantáceas catarinenses. In: Reitz, R. (ed.). Flora ilustrada catarinense. Herbário Barbosa Rodrigues, Itajaí. 44p.

Roldán, F.J. \& Kuijt, J. 2005. A new, red-flowered species of Tripodanthus (Loranthaceae) from Colombia. Novon 15: 207-209.

Thiers, B. 2013 [continuamente atualizado]. Index herbariorum: a global directory of public herbaria and associated staff. New York Botanical Garden's Virtual Herbarium. Disponível em <http:// sweetgum.nybg.org/ih/>. Acesso em 15 maio 2013.

Vidal-Russell, R. \& Nickrent, D.L. 2008. Evolutionary relationships in the showy mistletoe family (Loranthaceae). American Journal of Botany 95: 1015-1029. 
